\title{
Erratum to: Identification of trace levels of selenomethionine and related organic selenium species in high-ionic-strength waters
}

Kelly L. LeBlanc ${ }^{1}$ - Josef Ruzicka ${ }^{3}$. Dirk Wallschläger ${ }^{2}$

Received: 27 November 2015 / Accepted: 27 November 2015 /Published online: 14 December 2015

(C) Springer-Verlag Berlin Heidelberg 2015

Erratum to: Anal Bioanal Chem

DOI 10.1007/s00216-015-9124-1

The publisher regrets that Equation 3 is missing from the original version of this article. Equation 3 is given below and the original article was corrected.

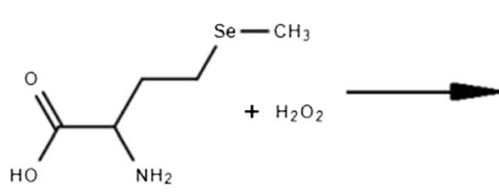

(1)

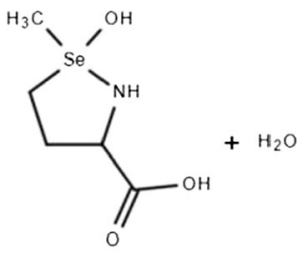

(4)

Our sincere apologies to the authors.

The online version of the original article can be found at http://dx.doi.org/ 10.1007/s00216-015-9124-1.

Kelly L. LeBlanc

kellyleblanc@trentu.ca

1 Environmental and Life Sciences Graduate Program, Trent University, 1600 West Bank Drive, Peterborough, ON K9J 7B8, Canada

2 Water Quality Centre, Environmental and Resource Sciences Program, and Department of Chemistry, Trent University, 1600 West Bank Drive, Peterborough, ON K9J 7B8, Canada

3 Thermo Fisher Scientific, 265 Davidson Avenue, Suite 101, Somerset, NJ 08873, USA 